\title{
A New Cooling Strategy in Curved Continuous Casting Process of Vanadium Micro-alloyed YQ450NQR1 Steel Bloom Combining Experimental and Modeling Approach
}

\begin{abstract}
KUN DOU and QING LIU
In the continuous casting process of steel, the bloom surfaces would experience intensive cooling from the water-cooled copper mold to secondary cooling water spray. If the cooling process is not controlled properly, hot ductility of the bloom surface microstructures would deteriorate, and bloom surface cracks would form easily under straightening deformation in a curved caster. Considering the above facts, the cooling scheme for the continuous casting of YQ450NQR1 steel bloom, a kind of vanadium-containing micro-alloyed steel, is studied with both experimental investigation and mathematical modeling in this work. The authors first investigate the hot ductility of bloom surface microstructures at various cooling rates using a Gleeble thermal simulator. Then, the precipitation of $\mathrm{V}(\mathrm{C}, \mathrm{N})$ particles and its influence on ferrite formation during continuous cooling are studied and characterized using High-Temperature Laser Scanning Confocal Microscopy. Based on these, the preferred cooling rate for surface microstructures at the straightening position in the caster is obtained. To further reduce the solute macro-segregation through enlargement of the equiaxed crystal zone, a cellular automaton-finite element model is used to calculate heat transfer and solidification structure evolution during the continuous casting process. After calibration with industrial trials, the model is utilized to determine the critical position for columnar to equiaxed transition and to adjust the pouring temperature for the melt. Combining the above research, a new cooling strategy for YQ450NQR1 steel bloom is obtained, which can improve crack resistance of bloom surface microstructures and reduce solute macro-segregation at the same time.
\end{abstract}

https://doi.org/10.1007/s11661-020-05819-9

(C) The Author(s) 2020

\section{INTRODUCTION}

IN the steel continuous casting process, the cooling condition in the mold region and the secondary cooling zone have predominant influence on the solidification structure and surface quality in the casting bloom. ${ }^{[1,2]}$ This phenomenon has been extensively researched in such works by $\mathrm{Liu}^{[3]}$ and Thomas. ${ }^{[4]}$ In a curved continuous caster, due to large cross section dimension and high thermal gradient from the bloom surface to center, the solidification structure tends to vary from the surface to center, ${ }^{[5,6]}$ with a thin layer of fine equiaxed grains initiated in the outer region ${ }^{[7]}$ and a columnar grain region stretching towards the bloom center. ${ }^{[8,9]}$

KUN DOU is with the Brunel Center for Advanced Solidification Technology (BCAST), Brunel University London, Kingston Lane, Uxbridge, UB8 3PH, UK. Contact e-mail: Kun.Dou@brunel.ac.uk QING LIU is with the State Key Laboratory of Advanced Metallurgy, University of Science and Technology. Beijing 100083, P.R. China. Manuscript submitted October 23, 2019.

Article published online May 18, 2020
Subsequently, with the decrease of the superheat and the forced convection in the molten steel, coarse equiaxed grains form eventually in the central area. ${ }^{[10-12]}$ According to the research from Dong, ${ }^{[13,14]}$ the columnar to equiaxed grain transition (CET) usually occurs in the secondary cooling zone during steel continuous casting, and it affects the solute macro-segregation behavior. Proper enlargement and refinement of the central equiaxed grain zone would reduce macro-segregation of the solute.

In a curved caster, the bloom undergoes deformation at the straightening position. ${ }^{[15,16]}$ If the secondary cooling is not controlled properly, the deformation-induced strain at the bloom surface/subsurface would exceed the critical value, ${ }^{[17-19]}$ causing surface cracks, which is a severe problem to the casting process and the downstream rolling process. ${ }^{[20,21]}$ The hot ductility of steel at high temperatures is a valuable index for judging the straightening temperature regarding certain steel grades and casting conditions. Metallurgists and casting engineers ${ }^{[22,23]}$ usually refer to plots between reduction of area (R.A.) curves and temperatures for steel hot 
ductility description. For straightening of steel in a curved continuous casting process, the typical strain rate is usually below $10^{-3} \mathrm{~s}^{-1}$. 24] The hot ductility curve usually comprises of two low ductility zones and one high ductility zone between them. ${ }^{[25,26]}$ Occurrence of low ductility zone for continuously cast steel during solidification and cooling is a combined result of phase transformation and secondary phase precipitation. According to Mintz $^{[19,22]}$ and some other researchers, ${ }^{[27-29]}$ it is recommended to keep R.A. value above 60 pet in order to avoid deformation-induced surface cracks. In actual steel continuous casting processes, the bloom surface temperature should be controlled to avoid the low ductility zones.

In this work, a type of vanadium-containing micro-alloyed YQ450NQR1 steel bloom $(360 \mathrm{~mm} \times 450 \mathrm{~mm}$ in cross section), which is produced by a curved caster, is used to analyze the solidification and cooling process. The hot ductility curves under various cooling rates are plotted after thermal testing with a Gleeble thermal simulator and the critical straightening temperatures at various cooling rates are determined. Moreover, the sample fracture morphologies and microstructures in low hot ductility regions are characterized using the scanning electron microscopy (SEM), the energy dispersive spectrometer (EDS), and the optical microscopy $(\mathrm{OM})$, respectively. Besides, the evolution of phases and the precipitation of the secondary particles during the continuous cooling process are observed in situ with the HTLSCM and further calibrated with the thermodynamic calculations. On this basis, the formation mechanism of the low ductility region is illustrated and the desired straightening temperature in the secondary cooling zone of the curved caster is determined. To further study the solidification structures and the solute macro-segregation in the bloom, a CA-FE model is established to determine the critical position along the casting direction where the CET starts. After calibration with the industrial trials, the influence of the superheat on the evolution of the equiaxed crystal ratio (ECR) and the average grain size is illustrated with the calculations and the optimal pouring temperature is determined. Finally, the cooling strategy for the YQ450NQR1 steel bloom in the curved caster is proposed which includes (1) Change in pouring temperature to control the CET and to reduce the solute macro-segregation and (2) Reallocation of the secondary cooling water amount to improve the ductility of the bloom surface microstructure and to reduce the surface cracks.

\section{EXPERIMENTS}

The cylindrical tensile samples (Figure 1) for the hot ductility tests are cut from the surface microstructures of the as-cast bloom. The hot ductility of the samples are tested using a Gleeble thermal simulator, the R.A. value of each sample is calculated using Eq. 1. Chemical compositions of the steel are shown in Table I. The experimental cooling rates $\left(0.5,1,3{ }^{\circ} \mathrm{C} / \mathrm{s}\right.$, ) are determined based on the actual temperature measurements during the continuous casting process on site. The thermal scheme for the hot ductility tests is shown in Figure 2. The fracture surfaces of the tensile samples are water quenched to keep the morphologies for further metallographic analysis.

$$
R \cdot A \cdot[\mathrm{pct}]=\left[1-\left(\frac{d_{2}}{d_{1}}\right)^{2}\right] \times 100 \mathrm{pct}
$$

where $d_{1}$ and $d_{2}$ are the sample diameter before and after hot ductility test.

After the hot ductility tests, the sample fracture surfaces are directly observed using the SEM. To further study the phase transformation behavior of the steel during the solidification and cooling process, a HTLSCM (as illustrated in Figure 3) with an infrared image furnace is employed for the "in situ" observation

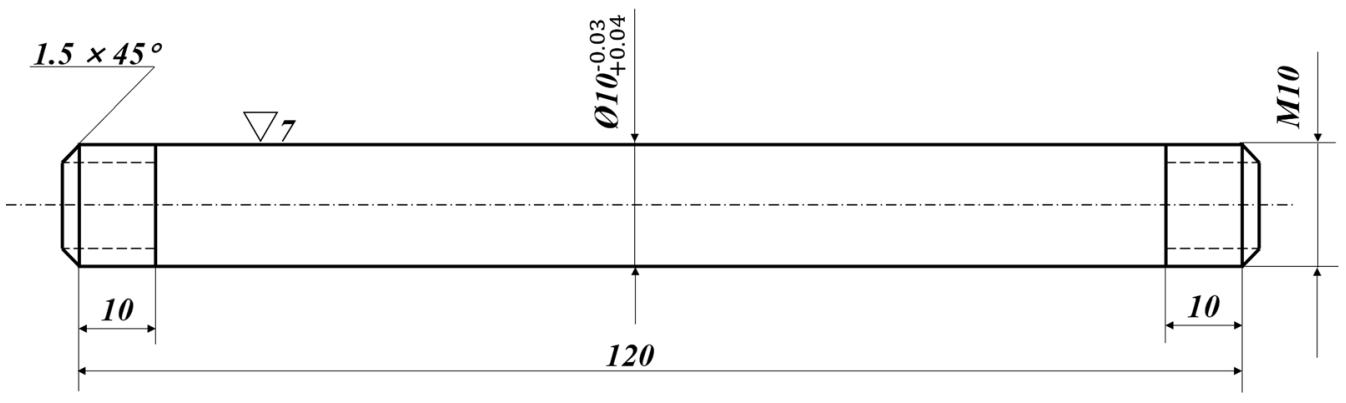

Fig. 1-Sample dimensions for hot ductility test.

Table I. Chemical Composition of the YQ450NQR1 Steel (Weight Percent)

\begin{tabular}{lccccccccccc}
\hline $\mathrm{C}$ & $\mathrm{Si}$ & $\mathrm{Mn}$ & $\mathrm{P}$ & $\mathrm{S}$ & $\mathrm{Cu}$ & $\mathrm{Cr}$ & $\mathrm{Ni}$ & $\mathrm{V}$ & $\mathrm{N}$ & $\mathrm{Fe}$ \\
\hline 0.123 & 0.42 & 1.33 & 0.012 & 0.0073 & 0.288 & 0.281 & 0.159 & 0.12 & 0.0125 & bal. \\
\hline
\end{tabular}




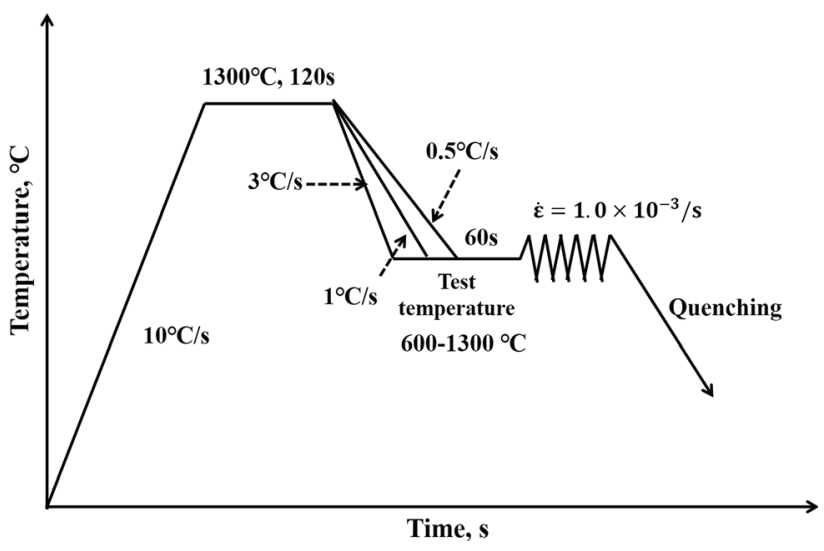

Fig. 2-Thermal scheme for the hot ductility tests at various cooling rates.

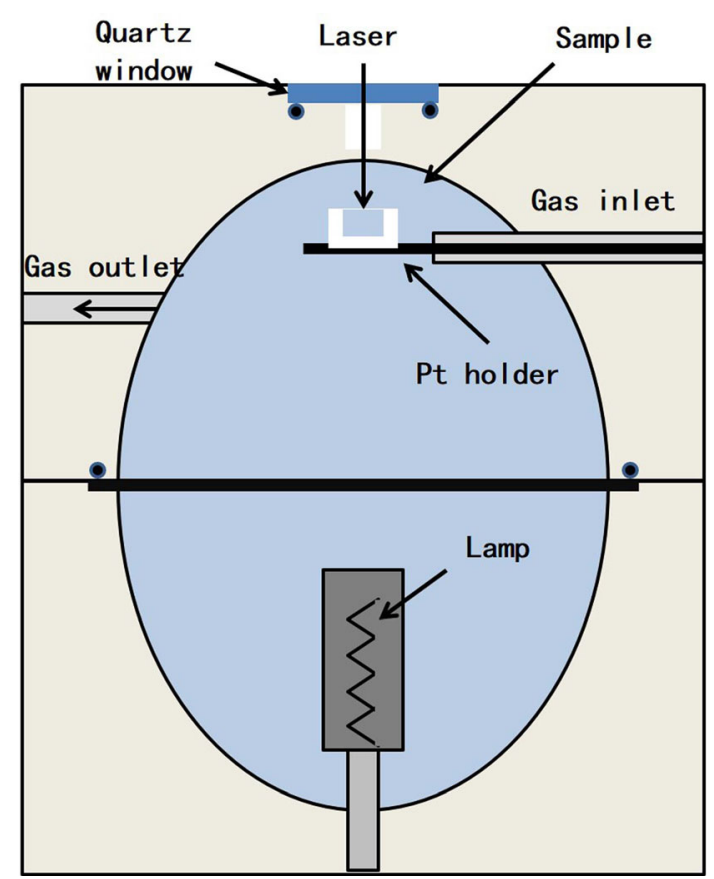

Fig. 3-Schematic illustration of the HTLSCM.

of the $\mathrm{V}(\mathrm{C}, \mathrm{N})$ precipitations and proeutectoid phase transformations. The samples are heated and cooled in an alumina crucible under the ultra-high-purity argon gas. The temperature is measured at the bottom of the holder in the crucible. The heat cycle is schematically shown in Figure 4. The samples are heated up to $1500{ }^{\circ} \mathrm{C}$ and held isothermally for $15 \mathrm{~min}$ to ensure that the $\mathrm{V}(\mathrm{C}, \mathrm{N})$ particles are completely dissolved, after which they are cooled to room temperature with the cooling rate $(V c)$ of 0.3 and $3{ }^{\circ} \mathrm{C} / \mathrm{s}$, respectively. Finally, the samples are mirror polished into metallographic specimen and etched using the 4 pct nital solution to further analyze the precipitations of the $\mathrm{V}(\mathrm{C}, \mathrm{N})$ using the SEM and the EDS.

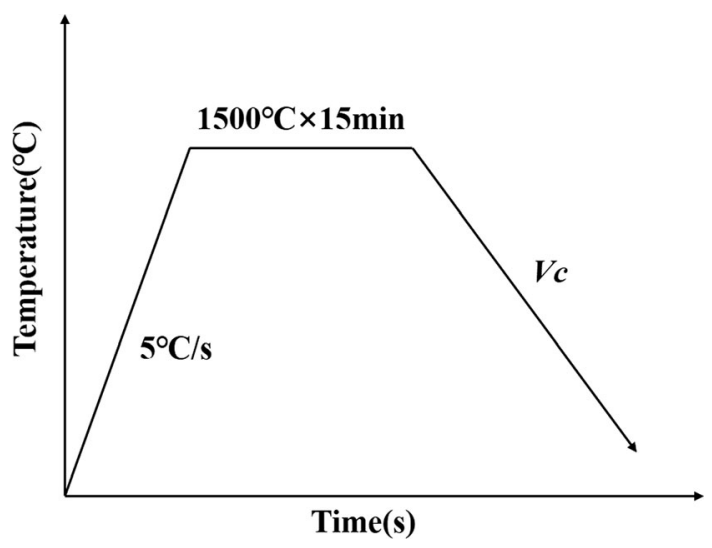

Fig. 4-Heat cycle of the in situ experiments.

\section{MODELING}

Based on experiments, a CA-FE model is further established to calculate the heat transfer and solidification structure evolution during the continuous casting process. Detailed descriptions and validations of the model can be tracked from some of the previous works. ${ }^{[30]}$ The operation parameters as well as the details of the cooling system in the continuous casting process which are used in this modeling work are shown in Tables II and III, respectively. The influence of the fluid flow on the heat transfer is considered by applying the modified thermal conductivity in the mushy zone of the casting bloom as is indicated in the previous work of the authors. A schematic illustration of the coupled CA-FE model is shown in Figure 5. In the calculation process, the macro heat flow in the casting bloom is first solved based on the finite element method. Then, the temperature information on the nodes of the finite element are interpolated onto the cellular automaton cells using the interpolation coefficients $(\emptyset$ values in Figure 5). The grain nucleation and growth are further calculated based on the model proposed by Gandin ${ }^{[36,37]}$ and Rappaz. ${ }^{[38]}$ In this modeling, only $1 / 4$ of the entire cross section $(360 \mathrm{~mm} \times 450 \mathrm{~mm})$ of the YQ450NQR1 steel bloom is selected as the calculation domain. To catch the thermal profile needed for the microstructure modeling, a timestep of 0.01 second is employed in the model. The finite element mesh size is 1 $\mathrm{mm}$, the CA cell size is $50 \mu \mathrm{m}$. The equations for heat flow, grain nucleation, and growth are listed below.

\section{A. Macro Heat Transfer}

Equation 2 is the two-dimensional heat transfer governing equation for the bloom continuous casting.

$$
\rho c \frac{\partial T}{\partial t}=\frac{\partial}{\partial x}\left(k_{\mathrm{eff}} \frac{\partial T}{\partial x}\right)+\frac{\partial}{\partial y}\left(k_{\mathrm{eff}} \frac{\partial T}{\partial y}\right)+S
$$

At the beginning of the casting process, the molten steel temperature equals to the pouring temperature, which is illustrated as $T(x, y, 0)=T_{\mathrm{c}}$, where $T_{\mathrm{c}}$ is the pouring temperature. 
Table II. Operation Parameters for YQ450NQR1 Steel Bloom

\begin{tabular}{lccccc}
\hline Cross Sectional Dimension & Pouring Temperature & Superheat & Casting Speed & Water Flowrate & Mold Length \\
\hline $360 \mathrm{~mm} \times 450 \mathrm{~mm}$ & $1550{ }^{\circ} \mathrm{C}$ & $37{ }^{\circ} \mathrm{C}$ & $0.5 \mathrm{~m} / \mathrm{min}$ & $0.35 \mathrm{~L} / \mathrm{kg}$ & $850 \mathrm{~mm}$ \\
\hline
\end{tabular}

Table III. Parameters of Secondary Cooling System for YQ450NQR1 Steel Bloom

\begin{tabular}{lcccccc}
\hline Segment Name & Foot Roller Zone & SCZ-I & SCZ-II & SCZ-III & SCZ-IV & Air Cooling Zone \\
\hline Segment Length $(\mathrm{m})$ & 0.40 & 1.97 & 2.06 & 5.11 & 5.14 & 14.07 \\
\hline
\end{tabular}

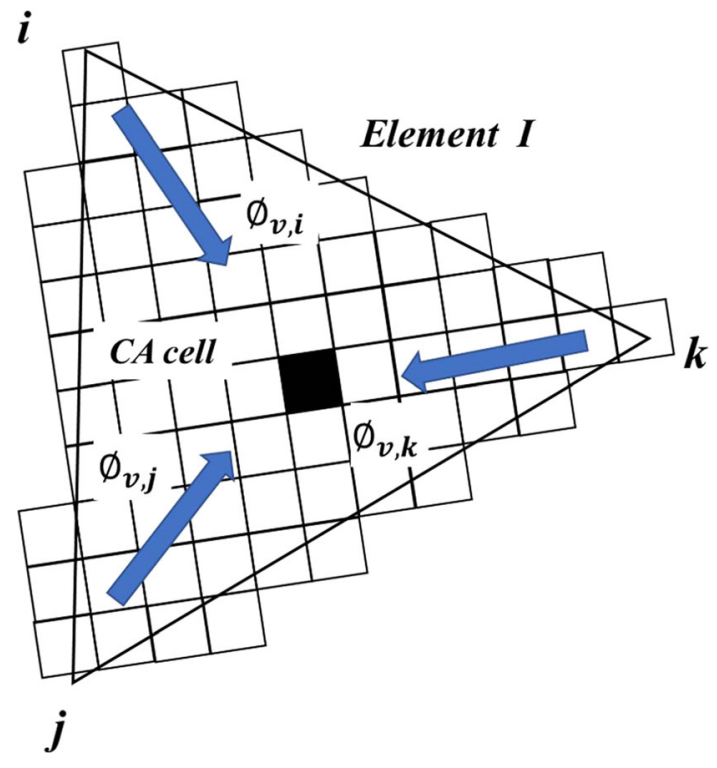

Fig. 5-Schematic illustration of the coupling between the finite element and the cellular automaton cell.

\section{B. Boundary Condition}

In the mold,

$$
-k_{\mathrm{eff}} \frac{\partial T}{\partial n}=\rho_{\mathrm{w}} c_{\mathrm{w}} W \frac{\Delta T}{A_{\mathrm{m}}}
$$

In the secondary cooling zone,

$$
-k_{\mathrm{eff}} \frac{\partial T}{\partial n}=h\left(T-T_{\mathrm{w}}\right)+\sigma \varepsilon\left[(T+298)^{4}-\left(T_{\mathrm{ext}}+298\right)^{4}\right]
$$

In the air cooling zone,

$$
-k_{\mathrm{eff}} \frac{\partial T}{\partial n}=\sigma \varepsilon\left[(T+298)^{4}-\left(T_{\mathrm{ext}}+298\right)^{4}\right]
$$

In the bloom center,

$$
-k_{\mathrm{eff}} \frac{\partial T}{\partial n}=0
$$

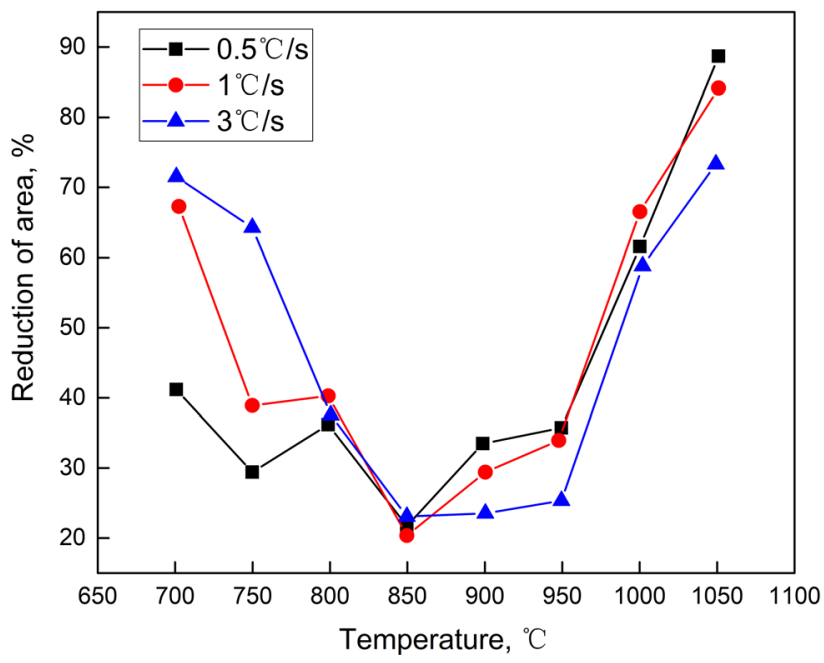

Fig. 6-Plots of the R.A. $v$ s the test temperatures at various cooling rates.

In all the above equations, $k_{\text {eff }}$ is the effective thermal conductivity, $\rho$ is the density of the molten steel, $\rho_{\mathrm{w}}$ is the water density, $c_{\mathrm{w}}$ is the specific heat capacity, $\mathrm{W}$ is the mold cooling water flow rate, $\Delta T$ is the temperature difference between the water that flows in and out of the mold, $A_{\mathrm{m}}$ is the surface area of the mold, $T_{\mathrm{w}}$ is the temperature of the cooling water, $h$ is the heat transfer coefficient between the mold and the bloom, $\sigma$ is the Stefan-Boltzmann constant, $\varepsilon$ is the radiation coefficient, and $T_{\text {ext }}$ is the external temperature.

\section{Heterogeneous Nucleation}

A continuous nucleation distribution function $\mathrm{d} n / \mathrm{d}(\Delta T)$ can be used to describe the change in the grain density, $\mathrm{d} n$, which is induced by an increase in the undercooling $\mathrm{d}(\Delta T)$. The distribution function $\mathrm{d} n / \mathrm{d}(\Delta T)$ is described by Eq.7.

$$
\frac{\mathrm{d} n}{\mathrm{~d}(\Delta T)}=\frac{n_{\max }}{\sqrt{2 \pi} \Delta T_{\sigma}} \exp \left[-\frac{1}{2}\left(\frac{\Delta T-\Delta T_{\max }}{\Delta T_{\sigma}}\right)\right]
$$

where $\Delta T$ is the calculated local undercooling, $\Delta T_{\max }$ is the mean undercooling, $\Delta T_{\sigma}$ is the standard deviation, 
Table IV. Nucleation Parameters Used in the Modeling

\begin{tabular}{lcccccc}
\hline \multicolumn{3}{c}{ Mold Surface Nucleation } & & \multicolumn{3}{c}{ Liquid Bulk Nucleation } \\
\cline { 1 - 3 }$n_{\text {max }, \mathrm{s}}\left(\mathrm{m}^{-2}\right)$ & $\Delta T_{\mathrm{n}, \mathrm{s}}\left({ }^{\circ} \mathrm{C}\right)$ & $\Delta T_{\sigma, \mathrm{s}}\left({ }^{\circ} \mathrm{C}\right)$ & & $n_{\max , \mathrm{b}}\left(\mathrm{m}^{-3}\right)$ & $\Delta T_{\mathrm{n}, \mathrm{b}}\left({ }^{\circ} \mathrm{C}\right)$ & $\Delta T_{\sigma, \mathrm{b}}\left({ }^{\circ} \mathrm{C}\right)$ \\
\hline$(1.2$ to 2.2$) \times 10^{8}$ & 1.0 & 0.1 & & $\left(1.6\right.$ to 3.2) $\times 10^{9}$ & 8 to 15 & 1.5 \\
\hline
\end{tabular}

and $n_{\max }$ is the maximum nucleation density which can be reached when all the nucleation sites are activated while cooling.

\section{Dendrite Tip Growth Kinetics}

The total undercooling of the dendrite tip, $\Delta T$, is considered as the sum of four contributions:

$$
\Delta T=\Delta T_{\mathrm{c}}+\Delta T_{\mathrm{t}}+\Delta T_{\mathrm{r}}+\Delta T_{\mathrm{k}}
$$

where $\Delta T_{\mathrm{c}}, \Delta T_{\mathrm{t}}, \Delta T_{\mathrm{r}}$, and $\Delta T_{\mathrm{k}}$ are the undercooling contributions associated with the solute diffusion, the thermal diffusion, the solid-liquid interface curvature, and the attachment kinetics, respectively. In order to accelerate the computation, the model is mathematically fitted, and the following equation is gained:

$$
v(\Delta T)=a_{2} \Delta T^{2}+a_{3} \Delta T^{3}
$$

where $a_{2}$ and $a_{3}$ are the coefficients of the multinomial of the dendrite tip growth velocity, and $\Delta T$ is the total undercooling of the dendrite tip. The influence of precipitations on grain formations are considered by properly selecting the nucleation parameters as indicated in Table IV, where $\mathrm{n}_{\max }$ is the maximum nuclei density, $\Delta T_{n}$ is the average nucleation undercooling, and $\Delta T_{\sigma}$ is the standard deviation for the nucleation undercooling.

\section{RESULTS}

\section{A. Hot ductility of the steel at various cooling rates}

Plots of the R.A. values vs the test temperatures at various cooling rates are shown in Figure 6. The phase evolution and precipitation for the YQ450NQR1 steel during the solidification and subsequent cooling are calculated using the open source thermodynamics library OpenCalphad, as is shown in Figure 7. It can be known that the austenite ( $\gamma$ phase) starts to form at $1482{ }^{\circ} \mathrm{C}$ and the $\alpha$-ferrite starts to form at $828^{\circ} \mathrm{C}$. As is seen in Figure 6, taking the critical R.A. value of $60 \mathrm{pct}$ as the lower bound, a high ductility zone exists either above $970{ }^{\circ} \mathrm{C}$ at the tested cooling rate or below $780{ }^{\circ} \mathrm{C}$ when the cooling rate is $3{ }^{\circ} \mathrm{C} / \mathrm{s}$. Another interesting phenomenon is that the R.A. value increases with the cooling rate when the test temperature is below $850{ }^{\circ} \mathrm{C}$, while it is the opposite when the test temperature exceeds $850{ }^{\circ} \mathrm{C}$. To further find the reason of such trend in the plots, the SEM is utilized to observe the fracture morphologies of the samples. Figure 8 shows the fracture morphologies of the samples at $800^{\circ} \mathrm{C}$ and $1050{ }^{\circ} \mathrm{C}$

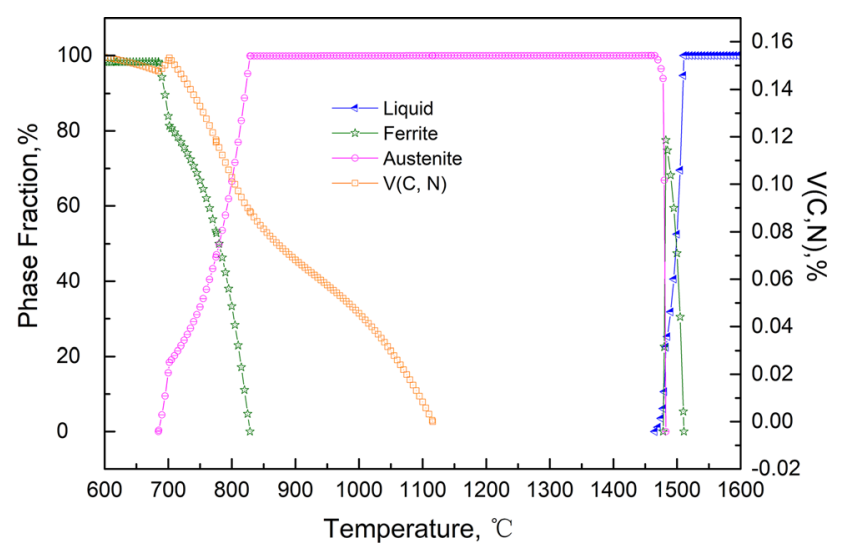

Fig. 7-The phase evolutions of the YQ450NQR1 steel during the solidification process.

with the cooling rates of $0.5,1$, and $3{ }^{\circ} \mathrm{C} / \mathrm{s}$, respectively. It can be seen from the fracture morphologies at $1050{ }^{\circ} \mathrm{C}$ (which is in the austenite region according to Figure 7), the sample fracture is trans-granular type, while at 800 ${ }^{\circ} \mathrm{C}$ where the $\alpha$-ferrite has formed, the sample fracture is intergranular type. At $1050{ }^{\circ} \mathrm{C}$, as the cooling rate decreases, the void size and fraction decrease, showing the signs of good hot ductility. At $800{ }^{\circ} \mathrm{C}$, with the increased cooling rate, the average grain size decreases, which contributes to the improvement of the hot ductility.

\section{B. In Situ Characterization of the Phase Transformation and the $V(C, N)$ Precipitation}

According to the thermodynamics calculation for the $\mathrm{V}(\mathrm{C}, \mathrm{N})$ precipitation in Figure 7 , it is found that the $\mathrm{V}(\mathrm{C}, \mathrm{N})$ particles start to precipitate at $\sim 1100{ }^{\circ} \mathrm{C}$ in the austenite region and continue to precipitate until the ferrite transformation occurs and finally deplete the remaining austenite.

Considering the micro-alloying function of vanadium, the $\mathrm{V}(\mathrm{C}, \mathrm{N})$ precipitation during the steel solidification process is vital for the hot ductility evolution, especially for the non-uniform cooling during the continuous casting process. To clarify the influence of $\mathrm{V}(\mathrm{C}, \mathrm{N})$ on the hot ductility, the HTCLSM is used to in situ observe the $\mathrm{V}(\mathrm{C}, \mathrm{N})$ precipitation and the ferrite transformation. Details about the experiment procedures can be found in the previous work. ${ }^{[31]}$ Figure 9 depicts the in situ phase evolutions at the cooling rate of 0.3 and $3^{\circ} \mathrm{C} / \mathrm{s}$, respectively. It can be observed that at low cooling rates, as the solidification continues, the $\alpha$-ferrite initiates from the grain boundaries and grows inward. With 

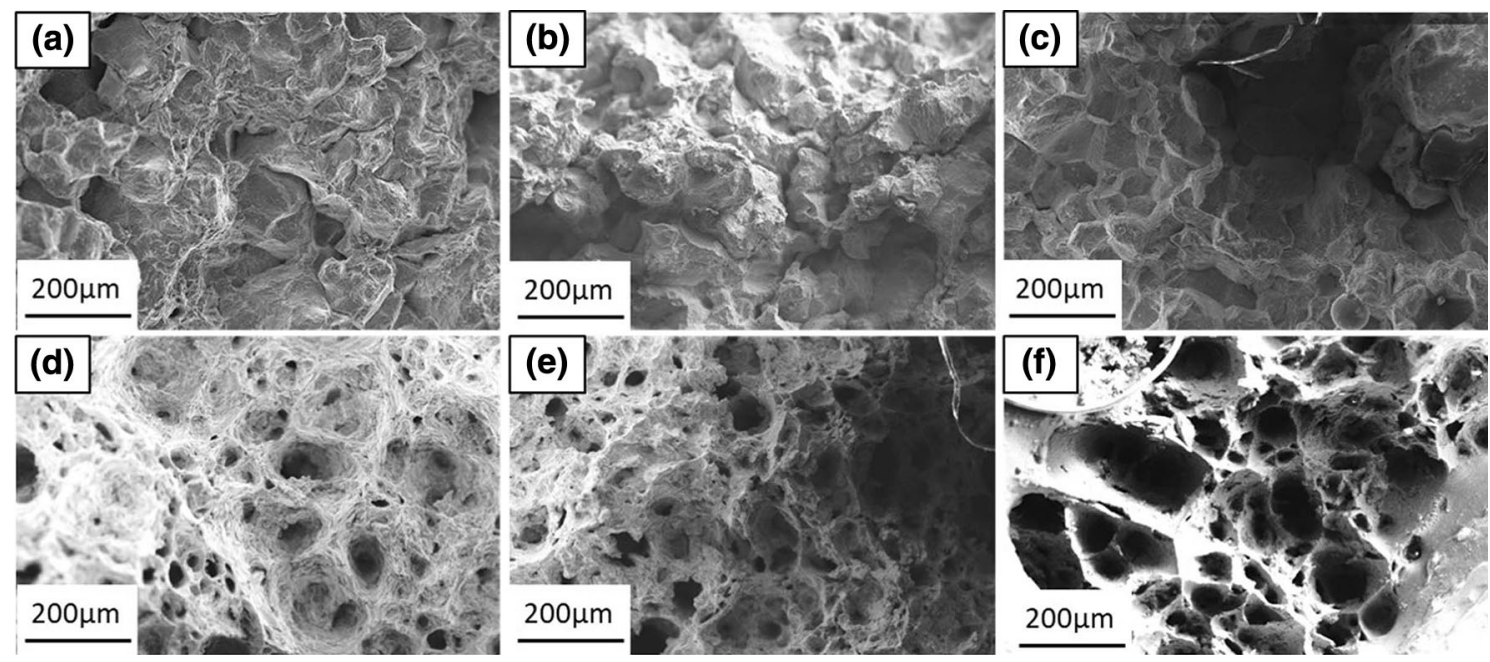

Fig. 8- The fracture morphologies of the samples at $800{ }^{\circ} \mathrm{C}(a, b, c)$ and $1050{ }^{\circ} \mathrm{C}(d, e, f)$ at the cooling rate of $0.5^{\circ} \mathrm{C} / \mathrm{s}(\mathrm{a}, \mathrm{d}), 1{ }^{\circ} \mathrm{C} / \mathrm{s}(\mathrm{b}, \mathrm{e})$, and $3^{\circ} \mathrm{C} / \mathrm{s}(\mathrm{c}, \mathrm{f})$.
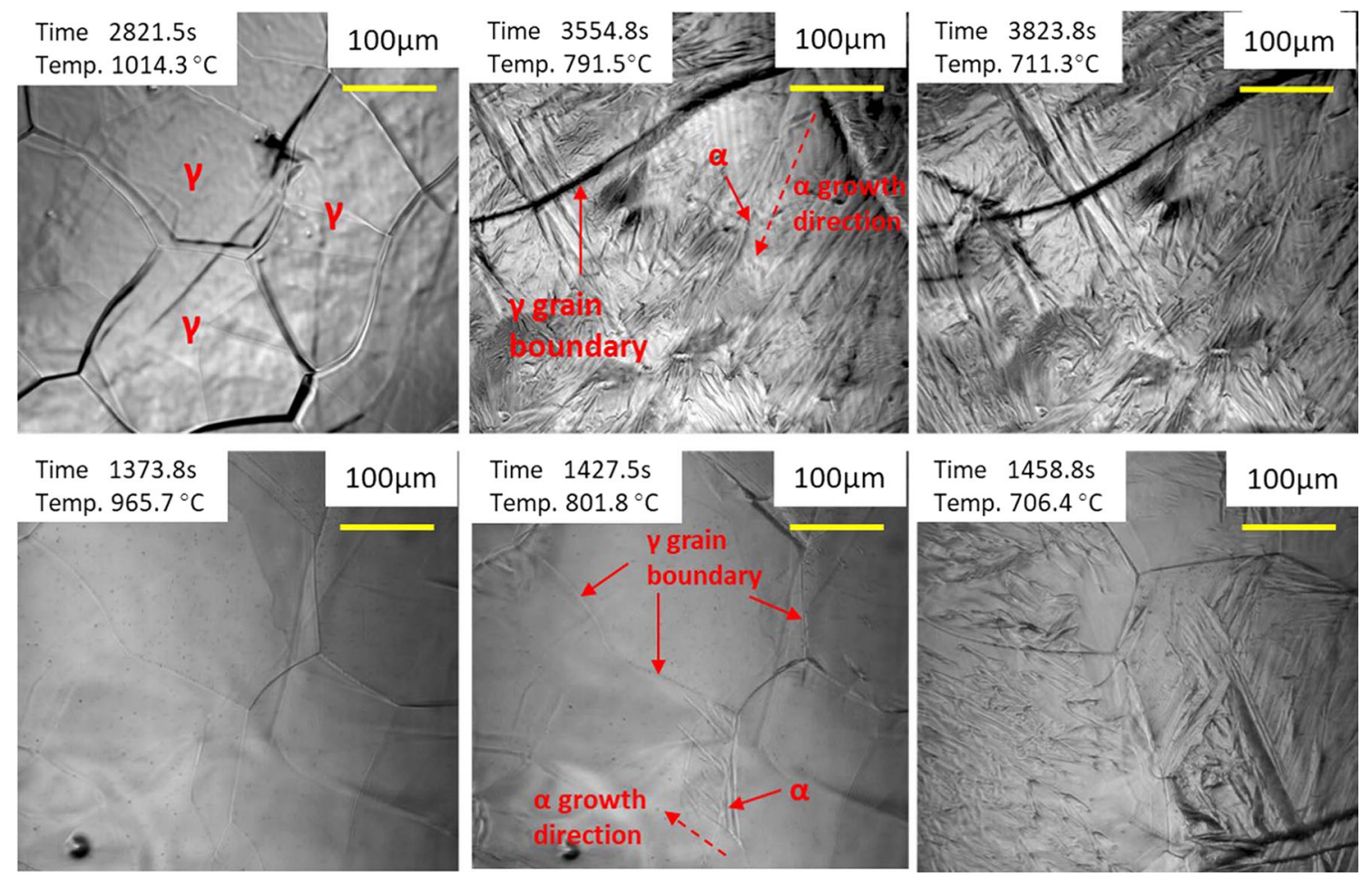

Fig. 9-In situ phase evolution during the solidification of the samples at the cooling rate of $0.3{ }^{\circ} \mathrm{C} / \mathrm{s}$ (first row) and $3{ }^{\circ} \mathrm{C} / \mathrm{s}$ (second row).

the increased cooling rate, some dark particles appear inside the austenite grains; subsequently, the ferrite initiates from the grain boundaries and from the grain interiors almost at the same time. As is found by Dippenaar ${ }^{[32,33]}$ and others, ${ }^{[34,35]}$ the dark particles are the direct signs of the $\mathrm{V}(\mathrm{C}, \mathrm{N})$ particles in this work. Hence the observed $\mathrm{V}(\mathrm{C}, \mathrm{N})$ precipitation behavior is in accordance with the calculation from Figure 7.
Furthermore, the samples after the HTCLSM observations are characterized using the SEM and the EDS, as is shown in Figure 10. It is clear that at low cooling rates, $\mathrm{V}(\mathrm{C}, \mathrm{N})$ precipitates along the austenite grain boundaries, while at high cooling rates, $\mathrm{V}(\mathrm{C}, \mathrm{N})$ particles tend to disperse inside the austenite grains. Based on the thermodynamic calculation and the experimental work, it can be concluded that the $\mathrm{V}(\mathrm{C}$, 


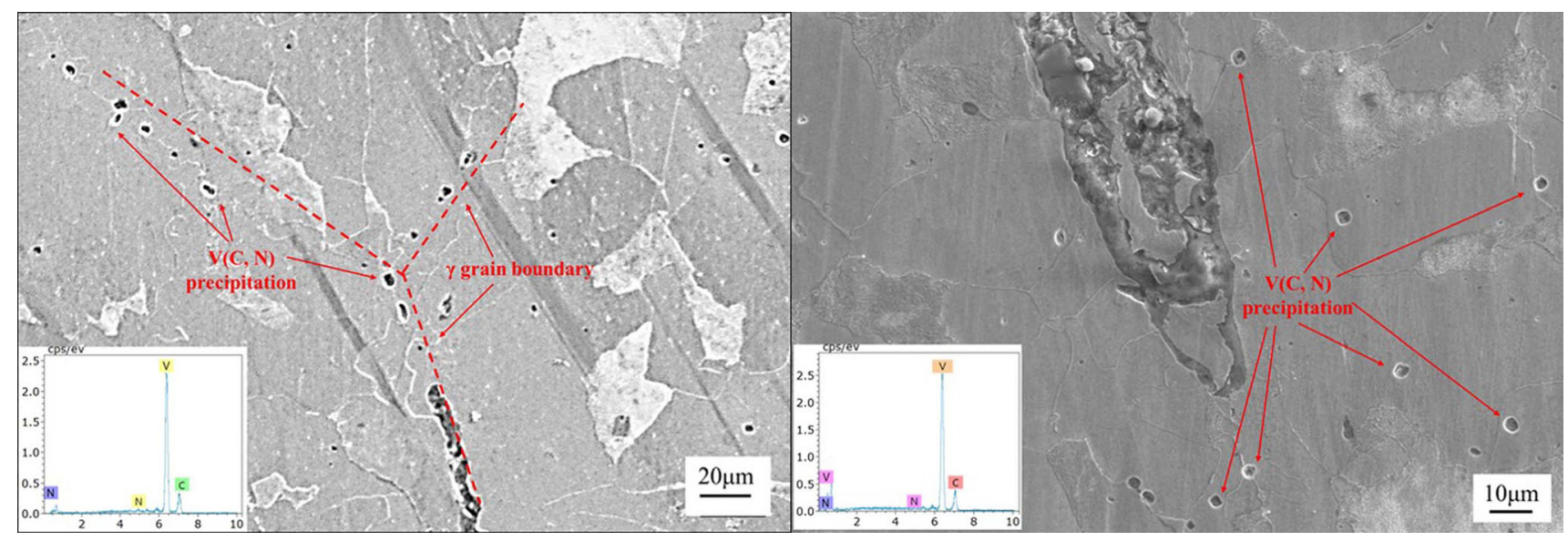

Fig. 10-SEM and EDS results of the $\mathrm{V}(\mathrm{C}, \mathrm{N})$ precipitation at the cooling rate of $0.3{ }^{\circ} \mathrm{C} / \mathrm{s}$ (left) and $3{ }^{\circ} \mathrm{C} / \mathrm{s}$ (right).

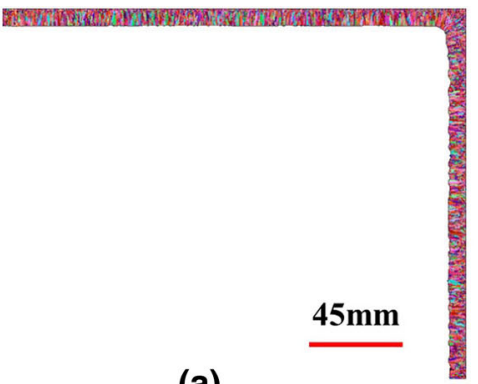

(a)

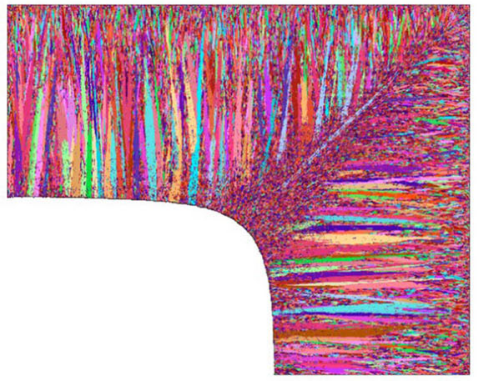

(d)

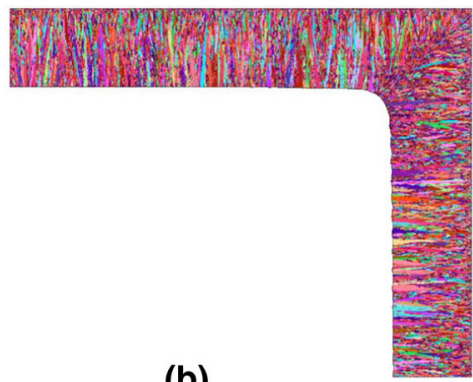

(b)

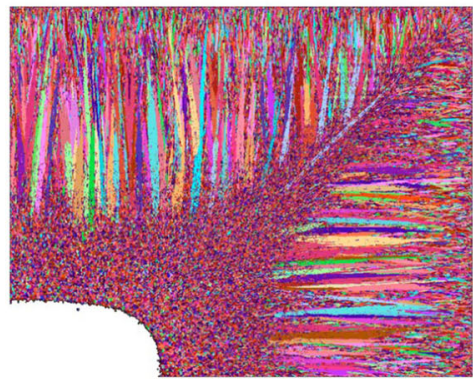

(e)

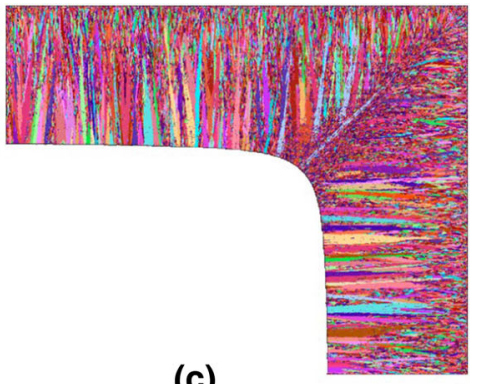

(c)

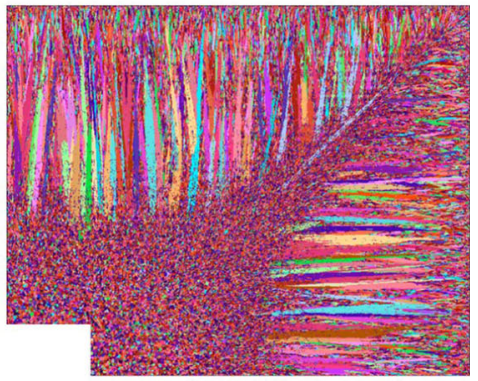

(f)

Fig. 11-The evolution of solidification structures and the CET at the cross section of the bloom along the casting direction, $(a) 0.39 \mathrm{~m}$ from the meniscus, $(b) 0.65 \mathrm{~m}$ from the meniscus, $(c) 2.65 \mathrm{~m}$ from the meniscus, $(d) 8.23 \mathrm{~m}$ from the meniscus, $(e) 11.12 \mathrm{~m}$ from the meniscus, and $(f)$ $15.82 \mathrm{~m}$ from the meniscus.

$\mathrm{N})$ acts as inoculant particles to promote the proeutectoid ferrite nucleation in the YQ450NQR1 steel continuous casting process.

\section{CA-FE Modeling of the Solidification Structure During the Steel Continuous Casting Process}

Figure 11 illustrates the evolution of the solidification structures along the casting direction based on the casting parameters from the industrial practice. It is found that the CET begins at the distance of $\sim 8.17 \mathrm{~m}$ from the meniscus, which is in the SCZ-III segment of the secondary cooling zone (SCZ) according to the caster parameters in Table III. Validations of the model are completed with the following two ways: (1) the bloom surface temperatures at multiple positions along the casting direction are measured using the infrared camera during the onsite casting process. In the 


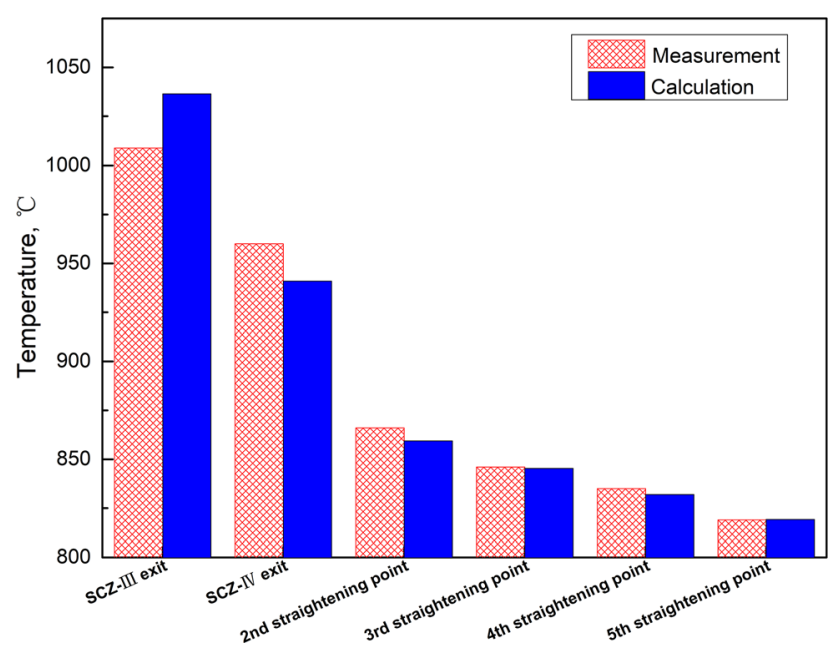

Fig. 12-Comparison of temperatures between the modeling and the measurements.

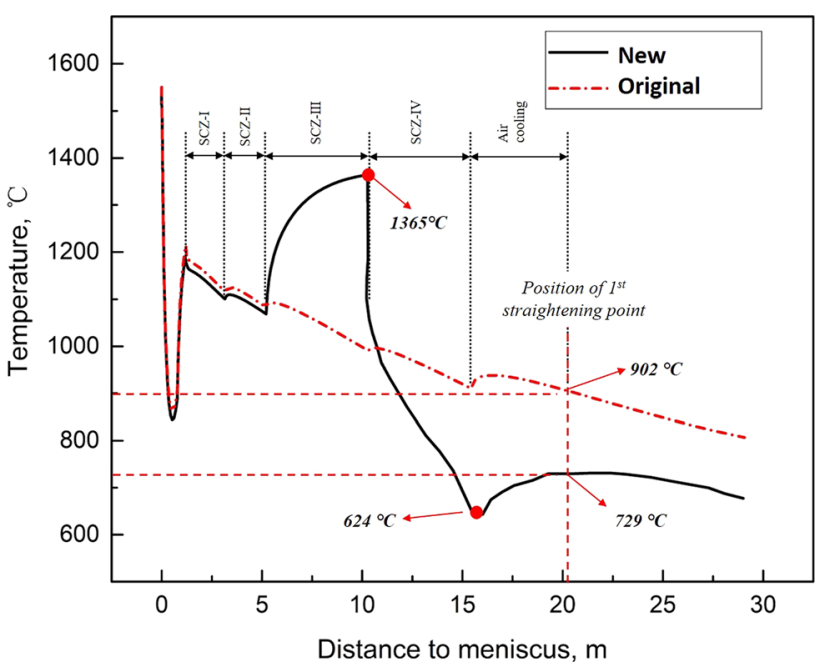

Fig. 13-The comparison of the bloom surface temperatures with the original and the new secondary cooling patterns.

meantime, the temperature distributions at the same positions from the modeling are compared as in Figure 12. (2) a slice of the bloom produced under the same casting condition is taken and the cross-sectional solidification structure is obtained after chemical etching. Two findings are worth mentioning according to the previous work ${ }^{[30]}$ : (1) the ECRs measured from the actual casting and the modeling results are 26.3 and 27.1 pct, which proves the accuracy of the model and (2) larger ECR can be achieved by employing lower pouring temperature; hence it is feasible to obtain an optimal pouring temperature in this work.

\section{DISCUSSIONS}

From the previous work, it is known that during the continuous casting process of the YQ450NQR1 steel, the straightening temperature falls into the low ductility zone when the secondary cooling is not controlled properly, which would cause the low ductility in the bloom surface/subsurface microstructures and result in frequent surface cracks. Moreover, due to the large cross section of the bloom, solute macro-segregation occurs easily. Based on this work, it is useful to properly control the pouring temperature and the secondary cooling scheme and to utilize the benefits of the central equiaxed grain zone and the fine surface microstructures containing dispersed $\mathrm{V}(\mathrm{C}, \mathrm{N})$ particles. In this way, the solute macro-segregation and the surface cracks can be reduced at the same time.

Based on the above analysis, a new cooling strategy is determined for the continuous casting process of the YQ450NQR1 steel after a series of calculation trials: the pouring superheat is $23{ }^{\circ} \mathrm{C}$ (the original value was 37 ${ }^{\circ} \mathrm{C}$ ), the water flowrate is $2.6 \mathrm{~L} / \mathrm{min}$ in the SCZ-III segment in the SCZ (the original water flowrate was 51.5 $\mathrm{L} / \mathrm{min}$ ), and the water flowrate is $165.6 \mathrm{~L} / \mathrm{min}$ in the SCZ-IV segment in the SCZ (the original water flowrate was $18.4 \mathrm{~L} / \mathrm{min})$. The surface temperatures from the bloom corners with the original and the new cooling schemes are shown in Figure 13.

According to the results from Section III-B and the thermodynamic calculations from Figure 7, the onset precipitation temperature for the $\mathrm{V}(\mathrm{C}, \mathrm{N})$ particles is $\sim 1100{ }^{\circ} \mathrm{C}$. From the heat transfer calculations (the original temperature curve from Figure 13) and the caster parameters (as shown in Table III), it can be judged that the $\mathrm{V}(\mathrm{C}, \mathrm{N})$ starts to precipitate mainly in the SCZ-III and the SCZ-VI segments in the SCZ, mainly in the bloom surface microstructures due to the intense water cooling. It is known from the above study that increased cooling rate can disperse the distribution of the $\mathrm{V}(\mathrm{C}, \mathrm{N})$, thus promoting the uniform distribution of the ferrite and the refinement of the grains. As a consequence, the hot ductility of the YQ450NQR1 steel at the straightening point can be improved to avoid the cracks. Based on the actual cooling condition and Figure 6, the bloom surface cooling rate in the SCZ-IV segment should be maintained above $1{ }^{\circ} \mathrm{C} / \mathrm{s}$ and the straightening temperature should be controlled between $700{ }^{\circ} \mathrm{C}$ and $800{ }^{\circ} \mathrm{C}$.

According to the temperature curve with the new cooling strategy in Figure 13, the bloom surface microstructures undergo a temperature increase in the SCZ-IV segment, which would promote the dissolving of the formerly precipitated $\mathrm{V}(\mathrm{C}, \mathrm{N})$ particles. In the SCZ-III segment, the bloom undergoes intensive cooling, which would lead to the re-precipitation and the dispersion of the $\mathrm{V}(\mathrm{C}, \mathrm{N})$ in surface microstructures. In this way, the hot ductility of the bloom surface is improved to resist the crack formation during the straightening operation.

According to Table III, the length of the SCZ-IV segment is $5.14 \mathrm{~m}$. Under the casting speed of $0.5 \mathrm{~m} /$ min, the surface temperature from the bloom corners decreases from $1365^{\circ} \mathrm{C}$ to $642{ }^{\circ} \mathrm{C}$ at the exit of the SCZ-IV segment, as the improvement in the surface microstructure ductility is the key factor in preventing the cracks formation during the straightening in continuous casting process. The R.A. values of the bloom 

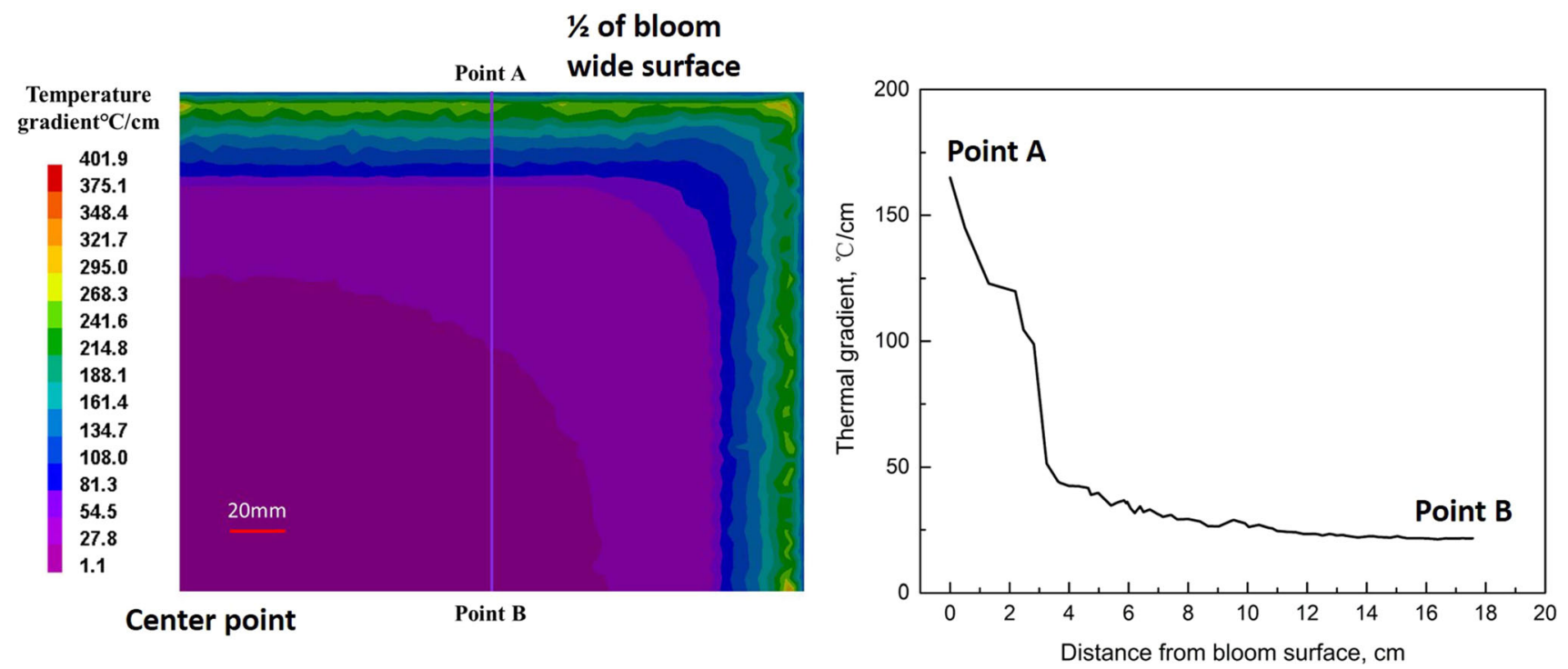

Fig. 14-Thermal gradient profile at bloom cross section with the new secondary cooling pattern (average values calculated between the SCZ-IV and the straightening point).
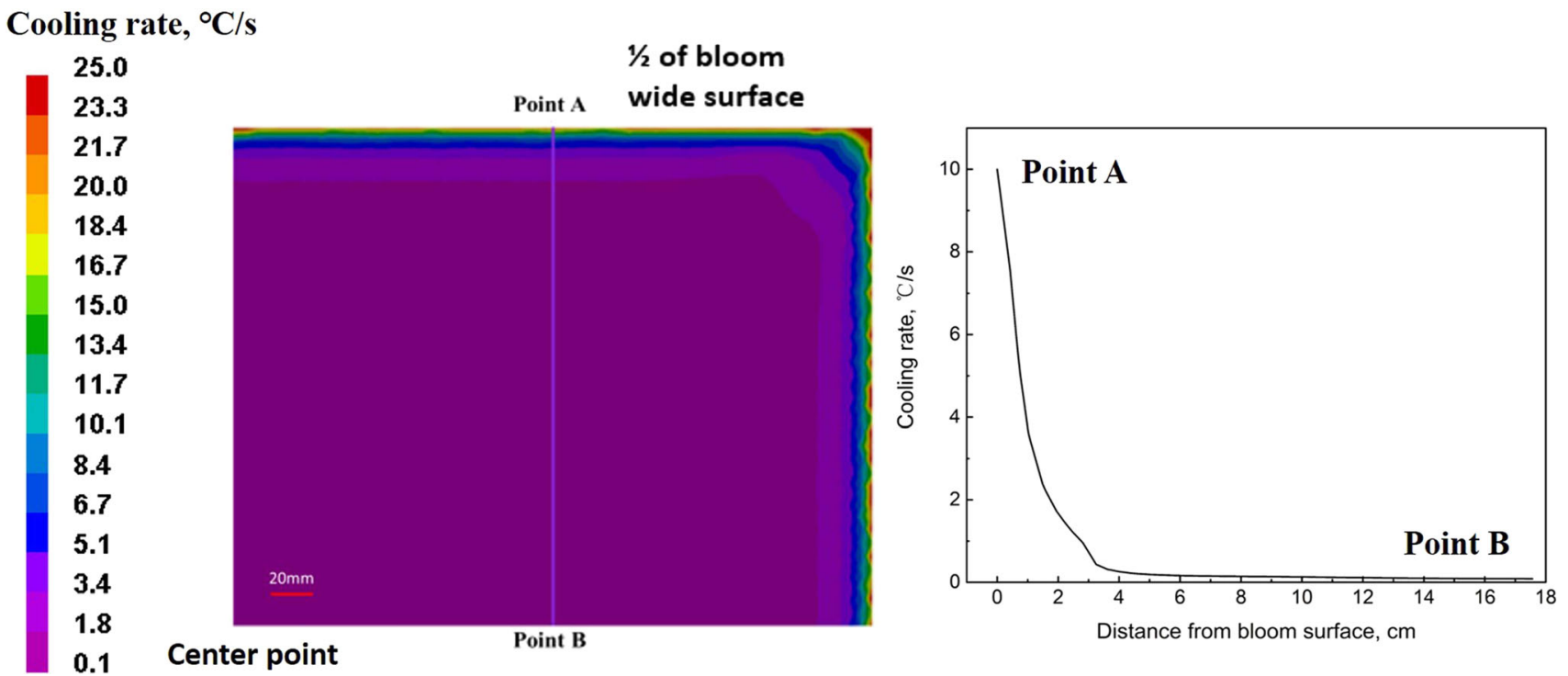

Fig. 15 - Cooling rate profile at the bloom cross section with the new secondary cooling pattern (average values calculated between the SCZ-IV and the straightening point).

surface and the subsurface should be above 60 pct. Considering this requirement and to further validate the idea, the thermal gradient and the cooling rate profiles (both are average values calculated between the SCZ-IV and the straightening point) at the bloom cross section under the new cooling strategy are obtained as in Figures 14 and 15; it can be seen that the variations of the thermal gradient and the cooling rate are large at the bloom surface, while it decreases and stabilizes at $\sim 3.5$ $\mathrm{cm}$ beneath the bloom surface. This indicates that the cooling water will have an influence on the subsurface microstructures within $3.5 \mathrm{~cm}$ from the bloom surface during the continuous casting process. Figure 16 shows the temperature profiles within $4 \mathrm{~cm}$ of the bloom surface along the cross section direction with the new secondary cooling pattern; it can be seen that within 3.5 
$\mathrm{cm}$ beneath the bloom surface, the temperatures are in the range from $720{ }^{\circ} \mathrm{C}$ to $750{ }^{\circ} \mathrm{C}$, all of which, according to Figure 6, fall within the high R.A. region. Based on the above analysis, the straightening temperature can be controlled to avoid the low ductility region. A further CA-FE modeling is carried out to compare the solidification structures of the YQ450NQR1 steel bloom with the original (left) and the new (right) secondary cooling patterns, as is shown in Figure 17. It is found that the ECR increases to 31.3 pct with the new cooling strategy, compared with the original ECR of 26.3 pct.

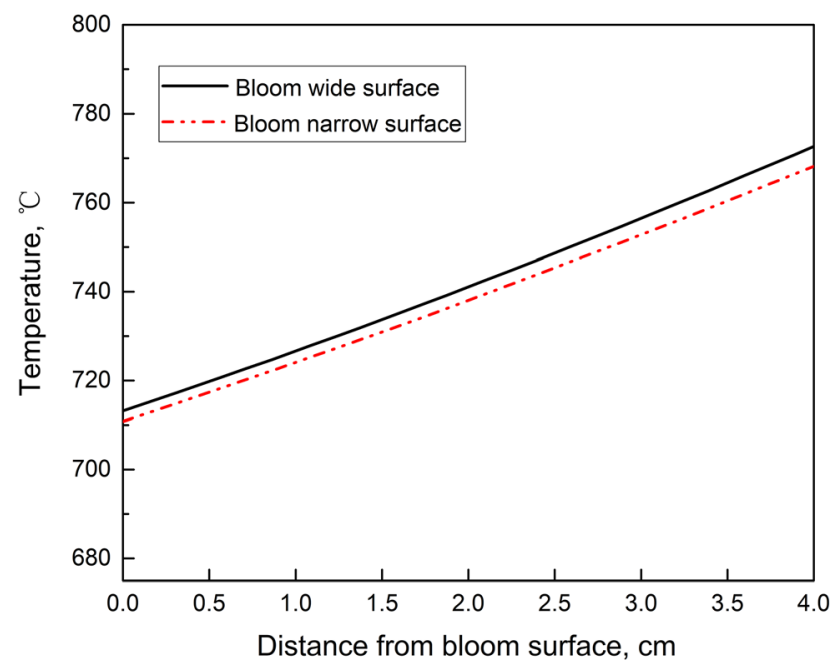

Fig. 16-Temperature profiles within $4 \mathrm{~cm}$ of the bloom surface along the cross section direction with the new secondary cooling pattern (calculated at the straightening position).

\section{CONCLUSIONS}

In this paper, a new cooling strategy for the curved continuous casting process of the vanadium-containing YQ450NQR1 steel is proposed based on the experimental and the modeling results. Main conclusions are as follows:

(1) The hot ductility of the YQ450NQR1 steel bloom at different temperatures varies with the cooling rates. The mechanism for the hot ductility evolution is a combined result of phase transformations and $\mathrm{V}(\mathrm{C}, \mathrm{N})$ precipitations.

(2) The HTCLSM is used to in situ observe the $\mathrm{V}(\mathrm{C}$, $\mathrm{N})$ precipitation and the ferrite formation at low/ high cooling rates. Combining the analysis of the HTCLSM samples with the SEM and the EDS, it is revealed that the increased cooling rates promote the dispersion of the $\mathrm{V}(\mathrm{C}, \mathrm{N})$ particles inside austenite grains, which makes the distribution of the ferrite more uniform, thus enhancing the hot ductility of the steel.

(3) Modeling of heat flow and solidification structure formation is carried based on a CA-FE model, and modeling results are validated against the temperature measurements and the macrostructure characterization. Based on these, the new pouring superheat is obtained to enlarge the ECR in the bloom central zone and to reduce the solute macro-segregation.

(4) A new cooling strategy is proposed based on the above findings in which the pouring superheat is $23{ }^{\circ} \mathrm{C}$, the water flowrate is $2.6 \mathrm{~L} / \mathrm{min}$ in the SCZ-III segment of the SCZ, and the water flowrate is $165.6 \mathrm{~L} / \mathrm{min}$ in the SCZ-IV segment of the SCZ. Using the new cooling strategy, the hot ductility of the surface/subsurface microstructures in the YQ450NQR1 steel bloom during the straightening deformation can be improved to avoid cracks and the ECR is increased from 26.3 to 31.3 pet.

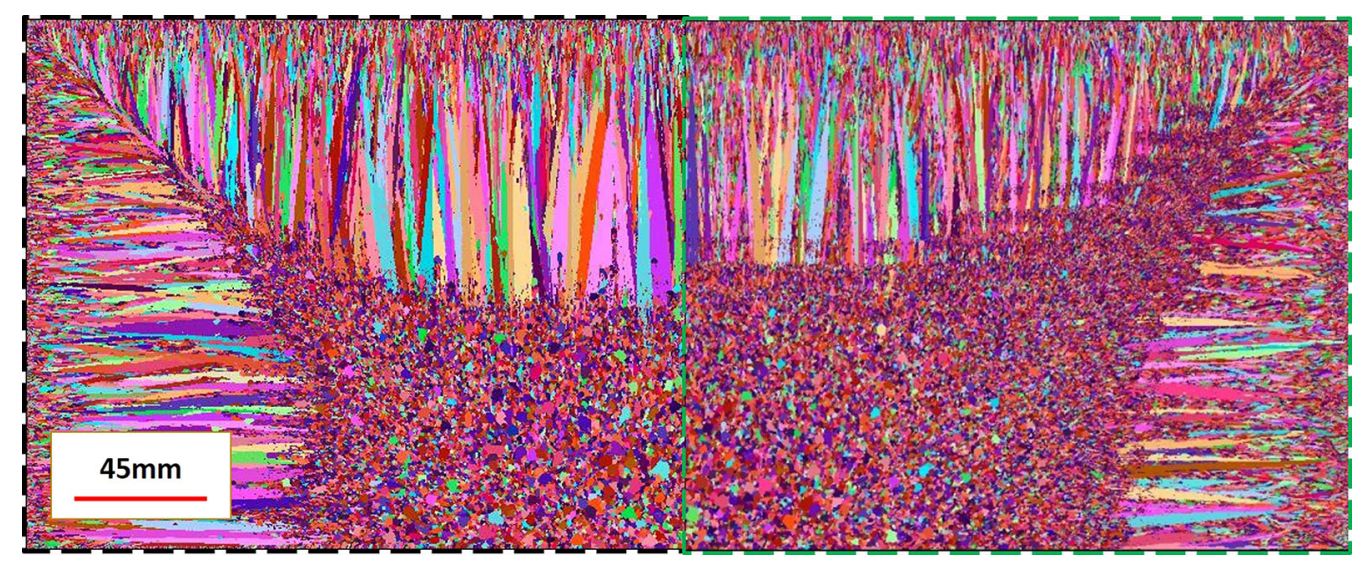

Fig. 17-Modeling results of the solidification structures for the bloom cross section with the original (left) and the new (right) secondary cooling pattern. 


\section{ACKNOWLEDGMENTS}

The authors would like to acknowledge the financial support for this study provided by Key Research \& Development Foundation (No. 41614014) and Independent Research \& Development Foundation (No. 41602023) of State Key Laboratory of Advanced Metallurgy, University of Science and Technology Beijing, China.

\section{OPEN ACCESS}

This article is licensed under a Creative Commons Attribution 4.0 International License, which permits use, sharing, adaptation, distribution and reproduction in any medium or format, as long as you give appropriate credit to the original author(s) and the source, provide a link to the Creative Commons licence, and indicate if changes were made. The images or other third party material in this article are included in the article's Creative Commons licence, unless indicated otherwise in a credit line to the material. If material is not included in the article's Creative Commons licence and your intended use is not permitted by statutory regulation or exceeds the permitted use, you will need to obtain permission directly from the copyright holder. To view a copy of this licence, visit http://creat ivecommons.org/licenses/by $/ 4.0 /$.

\section{REFERENCES}

1. G. Krauss: Metall. Mater. Trans. B, 2003, vol. 34B, pp. 781-92.

2. Raudensky and J. Horsky: Ironmak. Steelmak., 2005, vol. 32, pp. 159-64.

3. R.A. Hardin, K. Liu, A. Kapoor, and C. Beckermann: Metall. Mater. Trans. B, 2003, vol. 34B, pp. 297-306.

4. J. Sengupta, B.G. Thomas, and M.A. Wells: Metall. Mater. Trans. A., 2005, vol. 36A, pp. 187-204.

5. Z.K. Liu, D. Pile, J.O. Andersson, and A. Brorson: Metall. Mater. Trans. A, 1994, vol. 25A, pp. 1550-53.

6. K. Jin, S.P. Vanka, and B.G. Thomas: Metall. Mater. Trans. B, 2018, vol. 49B, pp. 1360-77.

7. M. Gonzalez, M.B. Goldschmit, A.P. Assanelli, E.F. Berdaguer, and E.N. Dvorkin: Metall. Mater. Trans. B, 2003, vol. 34B, pp. 455-73.

8. H. Zhong, X. Chen, Q. Han, K. Han, and Q. Zhai: Metall. Mater. Trans. B, 2016, vol. 47B, pp. 2963-70.

9. C.A. Santos, J.A. Spim, and A. Garcia: Eng. Appl. Artif. Intell., 2018, vol. 17, pp. 667-76.

10. W. Kurz, C. Bezençon, and M. Gäumann: Sci. Technol. Adv. Mater., 2001, vol. 2, pp. 185-91.
11. J.A. Spittle: Int. Mater. Rev., 2006, vol. 51, pp. 247-69.

12. J.D. Roehling, D.R. Coughlin, J.W. Gibbs, J.K. Baldwin, J.C. Mertens, G.H. Campbell, A.J. Clarke, and J.T. McKeown: Acta Mater., 2017, vol. 131, pp. 22-30.

13. W.U. Mirihanage, H. Dai, H. Dong, and D.J. Browne: Adv. Eng. Mater., 2013, vol. 15, pp. 216-29.

14. H.B. Dong and P.D. Lee: Acta Mater., 2005, vol. 53, pp. 659-68.

15. S. Medina, I. Ruiz-Bustinza, J. Robla, and J. Calvo: Metals, 2017, vol. 7, pp. 45-54.

16. B. Mintz and J.R. Banerjee: Mater. Sci. Technol., 2010, vol. 26, pp. 547-51.

17. A. Maurya and P.K. Jha: J. Inst. Eng. Ser. C, 2017, vol. 98, pp. 45-52.

18. K. Schwerdtfeger and H. Sha: Metall. Mater. Trans. B, 2010, vol. 31B, pp. 813-26.

19. B. Mintz and J.M. Arrowsmith: Met. Technol., 1979, vol. 6, pp. 24-32.

20. S.K. Giri, T. Chanda, S. Chatterjee, and A. Kumar: Mater. Sci. Technol., vol. 30, pp. 268-76.

21. L. Zhang, X. Yang, S. Li, M. Li, and W. Ma: JOM, 2014, vol. 66, pp. 1711-20.

22. B. Mintz, S. Yue, and J. Jonas: Int. Mater. Rev., 1991, vol. 36, pp. $187-220$.

23. A.S. Hamada and L.P. Karjalainen: Mater. Sci. Eng. A, 2011, vol. 528, pp. 1819-27.

24. I. Mejía, A. Bedolla-Jacuinde, C. Maldonado, and J.M. Cabrera: Mater. Sci. Eng. A, 2011, vol. 528, pp. 4133-40.

25. C.H. Lee, J.Y. Park, J.H. Chung, D.B. Park, J.Y. Jang, S. Huh, S. Ju Kim, J.Y. Kang, J. Moon, and T.H. Lee: Mater. Sci. Eng. A, 2016, vol. 651, pp. 192-97.

26. P. Lan, H. Tang, and J. Zhang: Mater. Sci. Eng. A, 2016, vol. 660, pp. $127-38$.

27. J. Sun and H. Yu: Mater. Sci. Eng. A, 2013, vol. 586, pp. 100-07.

28. B. Mintz: Ironmak. Steelmak., 2000, vol. 27, pp. 343-47.

29. I. Mejía, G. Altamirano, A. Bedolla-Jacuinde, and J.M. Cabrera: Metall. Mater. Trans. A., 2013, vol. 44A, pp. 5165-76.

30. K. Dou, L. Wang, J. Qing, X. Zhang, B. Wang, B. Liu, and Q. Liu: Advances in the Science and Engineering of Casting Solidification: An MPMD Symposium Honoring Doru Michael Stefanescu, Wiley, New York, 2015, pp. 173-80.

31. K. Dou, L. Meng, Q. Liu, B. Liu, and Y. Huang: Met. Mater. Int., 2016, vol. 22, pp. 349-55.

32. S. Griesser and R. Dippenaar: ISIJ Int., 2014, vol. 54, pp. 533-35.

33. D. Phelan and M. Reid: R. DippenaarComput. Mater. Sci., 2005, vol. 34, pp. 282-89.

34. C. Slater, K. Hechu, and S. Sridhar: Mater. Charact., 2017, vol. 126 , pp. $144-48$.

35. B. Hu and I.M. Richardson: Mater. Sci. Eng. A, 2006, vol. 429, pp. 287-94.

36. C.A. Gandin and M. Rappaz: Acta Metall., 1994, vol. 42, pp. 2233-46.

37. M. Rappaz and C.A. Gandin: Acta Metall., 1993, vol. 41, pp. 345-60.

38. C.A. Gandin, J.L. Desbiolles, M. Rappaz, and Ph. Thévoz: Metal. Trans. A, 1999, vol. 30, pp. 3153-65.

Publisher's Note Springer Nature remains neutral with regard to jurisdictional claims in published maps and institutional affiliations. 